\title{
Caracterização do uso de malhadeiras pela frota pesqueira que desembarca em Manaus e Manacapuru, Amazonas
}

\author{
Valdelira Lia Araújo FERNANDES ${ }^{1}$, Rafaela Nascimento VICENTINI², Vandick da Silva BATISTA3
}

\section{RESUMO}

A malhadeira é um apetrecho de pesca frequentemente utilizado na pesca regional. O presente estudo visa verificar características das malhadeiras utilizadas nos diversos subsistemas da Amazônia Central, seu uso e a aplicação de normas legais relacionadas. Os dados foram obtidos por meio de entrevistas com pescadores em Manaus entre 1994 e 2004 e em Manacapuru entre 2001 e 2004. Os resultados indicaram que o apetrecho responde em média a 14\% da produção pesqueira de Manaus, com tendência a diminuição e a 24,5\% de Manacapuru, com estabilidade interanual. As freqüências modais recentes do tamanho de malha estiveram entre 50-60 mm no desembarque em Manaus, mas em Manacapuru foram mais diversas, entre $20 \mathrm{~mm}$ e $90 \mathrm{~mm}$. A moda do comprimento das redes foi de $100 \mathrm{~m}$ em ambos portos, mas se em Manaus correspondem a cerca de $90 \%$ das registradas, em Manacapuru não são nem 50\% do total. Quanto à freqüência de ocorrência de uso da malhadeira nos subsistemas da Amazônia Central que desembarcaram em Manaus, destaca-se o rio Purus (47,8\%), enquanto que para Manacapuru predominou explotação no Baixo Solimões (94,3\%). A composição das capturas variou entre os anos analisados, destacando cinco principais pescados que compõem mais de $70 \%$ das capturas: tambaqui, aruanã, tucunaré, curimatá, pirapitinga. Com relação às restriçôes no tamanho de malha, a maioria dos apetrechos têm tamanho de malha passível de uso ilegal, similarmente aos comprimentos das mesmas. Concluiu-se que há grande diversidade de formas de uso do apetrecho, sendo necessário gerar normas legais mais efetivas e compatíveis com a realidade pesqueira, cultural e sócio-econômica da Amazônia.

PALAVRAS-CHAVE: Pesca artesanal, Malhadeira, Ordenamento, Amazônia Central.

\section{Characterization of gillnet fisheries landed in Manaus and Manacapuru, Central Amazon}

\section{ABSTRACT}

The gillnet is frequently used in Amazon commercial and artisanal fishing. The present study aims to verify characteristics of the gill-nets of gillnets found in various Central Amazon subsystems, their use, and compliance with related legal norms. Daily Interviews were made from 1994 to 2004 in Manaus, and from 2001 to 2004 in Manacapuru. The results indicated that the gillnet was responsible for about $14 \%$ of the yield landed in Manaus, with a tendency to diminish, but a stable $24,5 \%$ in Manacapuru. Modal mesh sizes were $50-60 \mathrm{~mm}$ in Manaus, but ranged from 20 to $90 \mathrm{~mm}$ in Manacapuru, and the modal length was $100 \mathrm{~m}$ for both. In Manaus this size accounted for about $90 \%$ of all gillnets recorded, but in Manacapuru it was less than 50\%. The Manaus fleet preferred to exploit the region of Purus (47,8\%), while the Manacapuru fleet preferred the Low Solimōes (94,3\%). The composition of gillnet catches varied during the interviewed years, but $70 \%$ of the total was usually made up of tambaqui, aruanã, tucunaré, curimatá, and pirapitinga. Most mesh sizes and lengths were illegal. We concluded that the legal norms for gillnet use should be adapted to fishery characteristics, but also to the socioeconomic and cultural reality of the Amazon.

KEY WORDS: Artisanal fisheries, Gillnet, Management, Fishery laws, Amazon

\footnotetext{
${ }^{1}$ Bolsista do CNPq/UFAM. Engenheira de Pesca, Universidade Federal do Amazonas, FCA/Laboratório de Avaliação e Manejo da Pesca-PYRÁ. E-mail: valdeliralia@yahoo.com.br

2 Bolsista do CNPq/INPA. Analista Ambiental. Núcleo de Recursos Pesqueiros - IBAMA/AM. E-mail: rafaela.vicentini@ibama.gov.br

${ }^{3}$ Bolsista do CNPq. Professor Titular, Universidade Federal de Alagoas, Instituto de Ciências Biológicas e da Saúde, LABMAR, Rua Aristeu de Andrade, 452, Farol, Maceió, Alagoas Brasil. CEP: 57021-090. E-mail: vbatista@pq.cnpq.br
} 


\section{INTRODUÇÃO}

Uma das principais características diferenciais das pescarias na Amazônia é a pesca multi-específica efetuada com multi-aparelhos (Petrere, 1978; Barthem et al., 1997). Dentre os aparelhos de pesca, a malhadeira apresenta grande importância para a pesca na região (Smith, 1979). Destacase como o como principal aparelho empregado na pesca realizada por ribeirinhos e como segundo mais empregado na pesca comercial que abastece Manaus e Manacapuru (Petrere, 1978; Merona \& Bittencourt, 1988; Batista, 1998; Batista et al., 1998).

A descrição geral do modo de utilização das malhadeiras na região Amazônica pode ser encontrada em trabalhos tradicionais sobre a pesca comercial na Amazônia (Petrere, 1978; Smith, 1979; Falabella, 1994). Porém poucos são os trabalhos com dados estatísticos de séries históricas que avaliem as características do uso destes apetrechos (e.g. Batista et al., 2004).

Restrições ao uso desse apetrecho de pesca têm sido freqüentemente adotadas entre as táticas de manejo aplicadas com fins de controlar a explotação dos recursos pesqueiros. São exemplos disto as seguintes normas: i) Portaria IBAMA 08/1996, a qual proíbe que redes de emalhar com comprimento superior a 150 metros sejam colocadas a a menos de $200 \mathrm{~m}$ das zonas de confluência de rios, lagos, igarapés e corredeiras em toda a bacia hidrográfica do rio Amazonas; ii) Portaria 466/1972 atualizada pela Instrução Normativa IBAMA 43/2004, de alcance nacional, a qual proíbe o uso de malhadeiras com malhas inferiores a 70 milímetros entre ângulos opostos, cujo comprimento ultrapasse a $1 / 3$ da largura do ambiente aquático;

Batista et al. (2004) apontaram tais normas como pouco respeitadas por serem inadequadas às condições social, cultural, ecológica e econômica da Amazônia. Neste contexto, Batista (1998) já ressaltava que para a administração pesqueira é prioritário compreender inicialmente como o explorador está utilizando os aparelhos disponíveis, para viabilizar estratégias de manejo mais realistas às características da região. De uma forma geral, as características da atividade devem ser monitoradas e seus resultados comparados com os objetivos e metas pretendidos pelas políticas públicas no setor.

Dada a necessidade de se conhecer o contexto tecnológico existente e sua aplicação considerando as normas legais em vigor, o objetivo principal do presente estudo é fornecer uma base de informação mais atualizada do uso da malhadeira pela pesca comercial de Manaus e Manacapuru, no período entre 1994 e 2004, para subsidiar a elaboração de medidas de manejo mais específicas e adequadas para regiōes da Amazônia Central. $\mathrm{O}$ trabalho também pretende analisar o cumprimento de algumas normas que regulamentam o seu uso na região.

\section{MATERIAL E MÉTODOS}

Foram analisados dados de desembarque pesqueiro provenientes da frota que desembarcou em Manaus, no período de 1994 a 2004, e em Manacapuru no período de 2001 a 2004. As informações analisadas são de operações de pesca efetuadas em parte do Sistema Solimões-Amazonas (Figura 1), que foram extraídas do banco de dados elaborado e mantido pelo Laboratório de Avaliação de Manejo da Pesca (LAMP), através do Projeto "Estatística Pesqueira" do Programa Integrado dos Recursos Aquático e da Várzea (PYRÁ), da Universidade Federal do Amazonas (UFAM).

As análises foram efetuadas por estatística descritiva a partir das seguintes informaçôes: data de desembarque; origem da embarcação; sub-sistema/rio/local de pesca; tamanho de malha entre nós opostos $(\mathrm{mm})$; comprimento $(\mathrm{m})$ da malhadeira; captura (quilograma) e espécies capturadas. Foram elaborados gráficos e tabelas cruzadas para representação dos resultados. $\mathrm{O}$ cálculo das medidas de tendência central e medidas de variação foram obtidos através de planilha eletrônica.

$\mathrm{Na}$ caracterização operacional das malhadeiras calculouse o percentual de utilização da malhadeira entre os diversos apetrechos e em relação aos principais subsistemas da Amazônia Central. Os locais de pesca foram classificados de acordo com os principais sub-sistemas da Amazônia Central: Alto Solimões, Jutai, Médio Solimões, Juruá, Japurá, Baixo Solimôes, Purus, Negro, Alto Amazonas, Madeira e Médio Amazonas, e locais não identificados (Figura 1).

As capturas mensais em cada ano foram estimadas a partir da quantidade desembarcada multiplicada por um fator de correção do mês. Este fator corrige duas lacunas registradas no trabalho cotidiano da coleta. A coleta foi diária, mas por problemas diversos, a coleta não foi efetivada em todos os dias em vários meses, assim, para este caso, foi registrado o número de dias com desembarque no mês e o número de dias com coleta, sendo efetuada a proporção para incorporação da produção estimada nos dias sem coleta pela média do mês. Similarmente, todos os barcos novos no porto deveriam ser entrevistados em todos os dias com coleta, porém responsáveis de algumas embarcações se recusaram a efetuar declarações sobre a viagem. Assim, todos os barcos presentes no porto foram registrados diariamente pelo seu nome no casco, e mensalmente comparados com a relação dos barcos com desembarque registrado, sendo efetuada nova proporção que gerou o segundo componente na correção do valor de produção mensal. Este conjunto de providências é sintetizado na seguinte fórmula:

$Y^{\prime}=\frac{Y}{\left(\frac{N D M-N D F}{N D M} * \frac{N B R-N B S E}{N B R}\right)}$ onde: 


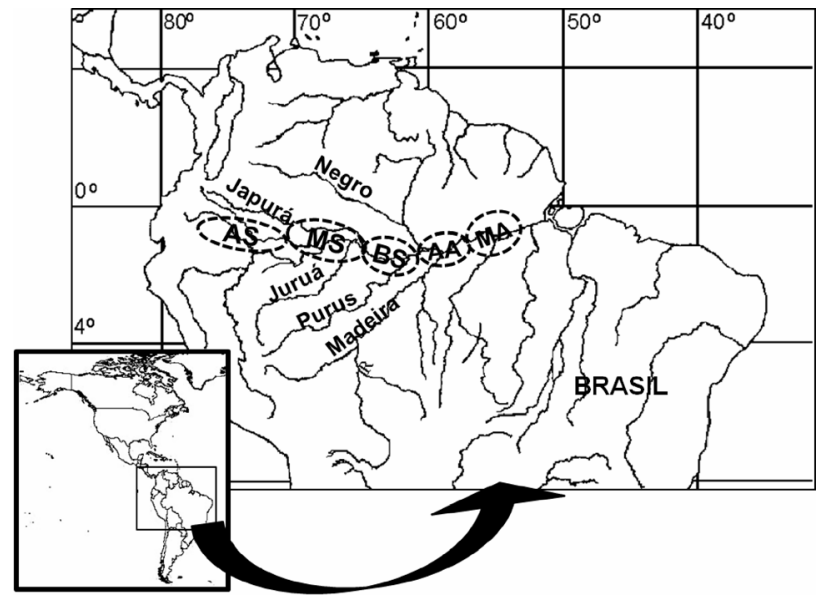

Figura 1 - Mapa do Estado do Amazonas com indicação dos principais subsistemas nos quais atuam a frota pesqueira regional: (AS) Alto Solimões; (MS) Médio Solimões; (BS) Baixo Solimões; (AA) Alto Amazonas; (MA) Médio Amazonas; rio Madeira; rio Purus; rio Juruá; rio Japurá; rio Negro.

$Y^{\prime}=$ Produção mensal corrigida

$\mathrm{Y}=$ Produção mensal registrada

NDF - Número de dias faltosos

NDM - Número de dias no mês

NBSE - Número de barcos presentes no porto no mês sem entrevistas efetivadas

NBR - Número de total de barcos registrados no porto no mês.

Em alguns meses há ausência de registros de capturas devido a malhadeira ter sido usada em combinação com outros aparelhos impedindo discriminar o apetrecho gerador da produção, não sendo assim incluídas nas análises. As espécies mais capturadas em peso no período total em cada porto foram representadas através do gráfico de setores.

Para avaliar a aplicação da Portaria 466/1972 e IN 47/2004, verificou-se o percentual de malhadeiras com tamanho de malha inferior a 70 milímetros a cada ano. Também se comparou o uso de malhadeiras com comprimento superior a 150 metros, antes e após a expedição da Portaria 008/1996 por meio do teste t para proporçôes (StatSoft, 1999).

\section{RESULTADOS}

PARTICIPAÇÃO DA MALHADEIRA NA PRODUÇÃO DESEMBARCADA EM MANAUS E MANACAPURU

A participação da malhadeira nos desembarques de pescado nos dois portos foi diferenciada e variada ao longo dos meses e em cada ano analisado (Figura 2). Em Manaus variou entre $1 \%$ (janeiro de 1994) e $42 \%$ (junho de 1995) com média de 14,47\% $( \pm 9,22)$. Em Manacapuru variou de
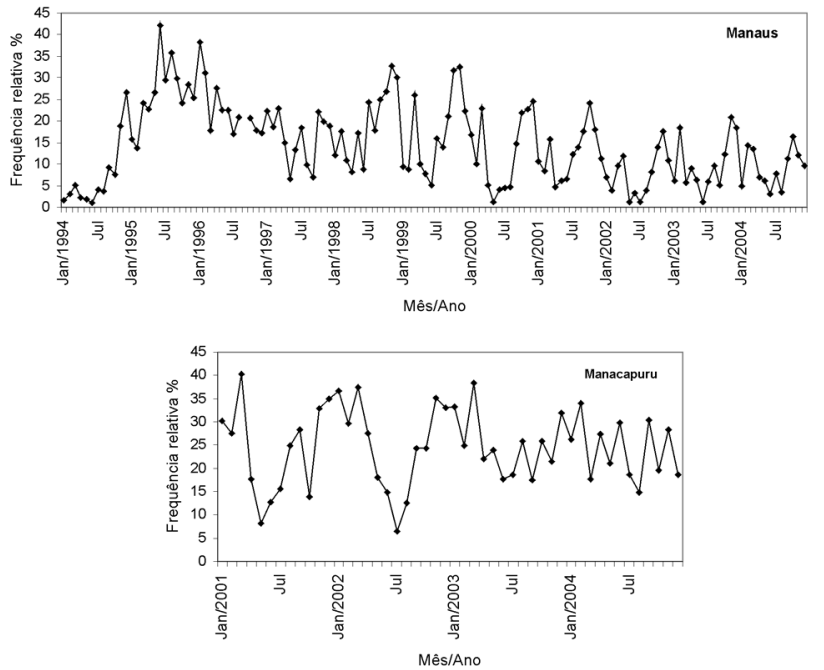

Figura 2 - Variação mensal e anual da participação da malhadeira em relação à produção total desembarcada em Manaus entre 1994 e 2004 (acima) e Manacapuru entre 2001 e 2004 (abaixo).

6\% (julho de 2002) e 40\% (março de 2001) com média de $24,45 \%( \pm 1,18)$.

A produção com malhadeira desembarcada em Manaus também foi maior em 1995 (Figura 3), sendo observado que houve diminuição gradual da produção da malhadeira ao longo dos anos analisados. Em todos os anos, a produção foi particularmente elevada (>100 t) entre setembro e novembro,
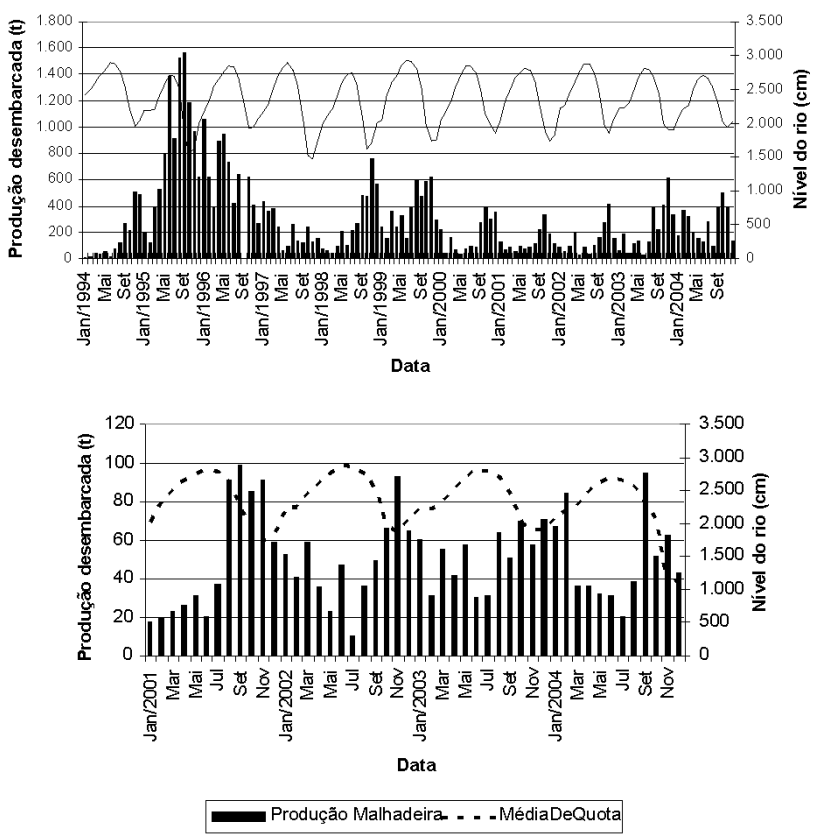

Figura 3 - Variação mensal e anual da produção pesqueira utilizando a malhadeira desembarcada em Manaus entre 1994 e 2004 (acima) e Manacapuru entre 2001 e 2004 (abaixo), com a indicação do nível médio do rio $(\mathrm{cm})$. 
período de seca fluvial. Já em Manacapuru, a produção anual com malhadeira se manteve entre 573 t e 611 t nos quatro anos, também havendo maior produção mensal entre agosto e dezembro (> $40 \mathrm{t}$ ).

\section{CARACTERIZAÇÃO FISICA DAS MALHADEIRAS UTILIZADAS NAS PESCARIAS}

Avaliando a freqüência anual relativa de ocorrência dos comprimentos de redes utilizadas nas pescarias (Figura 4), observou-se tanto a maior participação da classe 100-120 metros, quanto o crescimento gradual na participação desta classe nos desembarques ao longo dos anos analisados. Comparando os portos, registrou-se que em Manaus a participação de redes desta classe está próxima de 100\%, enquanto que em Manacapuru ainda não alcançou os $50 \%$, sendo tipificado o uso de malhadeiras menores.
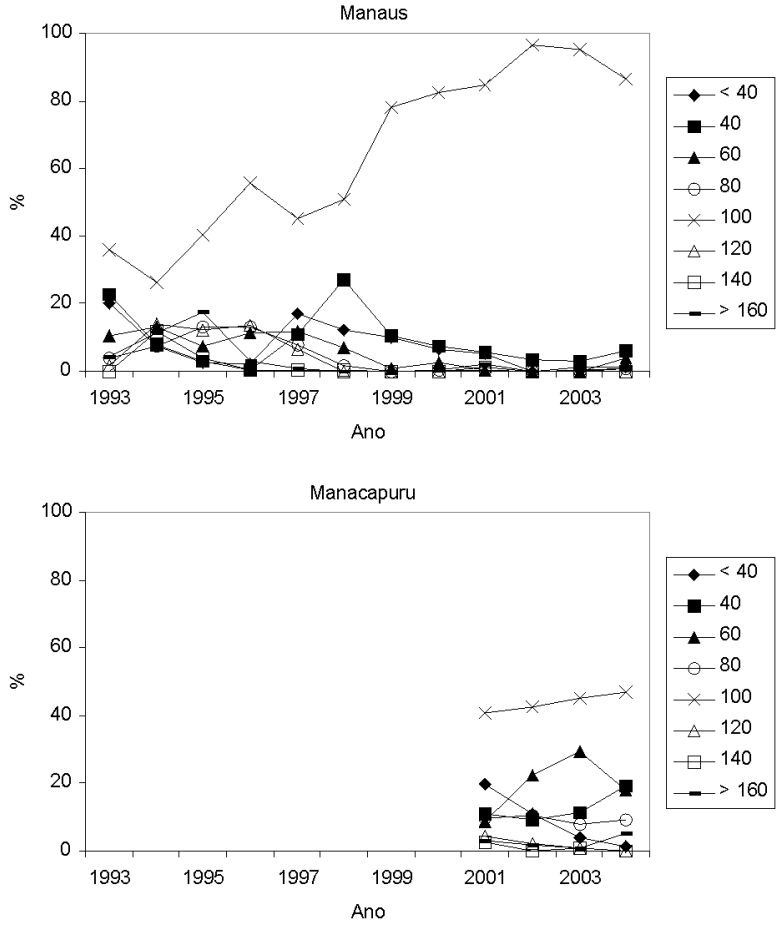

Figura 4 - Freqüência relativa do comprimento das malhadeiras utilizadas pela frota que desembarcou em Manaus (acima) entre 1994 e 2004 e Manacapuru (abaixo) entre 2001 e 2004.

Comparando a freqüência relativa dos tamanhos de malhas utilizados nas capturas com malhadeira por ano (Figura 5), observou-se em Manaus que entre 1994 e 1997 houve maior utilização de redes com malhas pertencentes às classes $20 \mathrm{~mm}$ a $60 \mathrm{~mm}$. Desde 1998 se registrou aumento nas freqüências de malhas entre $50 \mathrm{~mm}$ e $70 \mathrm{~mm}$, e entre 1998 e 2001 para redes com malha de 100-120 mm, o que não se manteve, voltando a ser maior para malhas menores, de 50-60 mm, entre 2001 e 2004. Já em Manacapuru a diversidade foi maior, variando
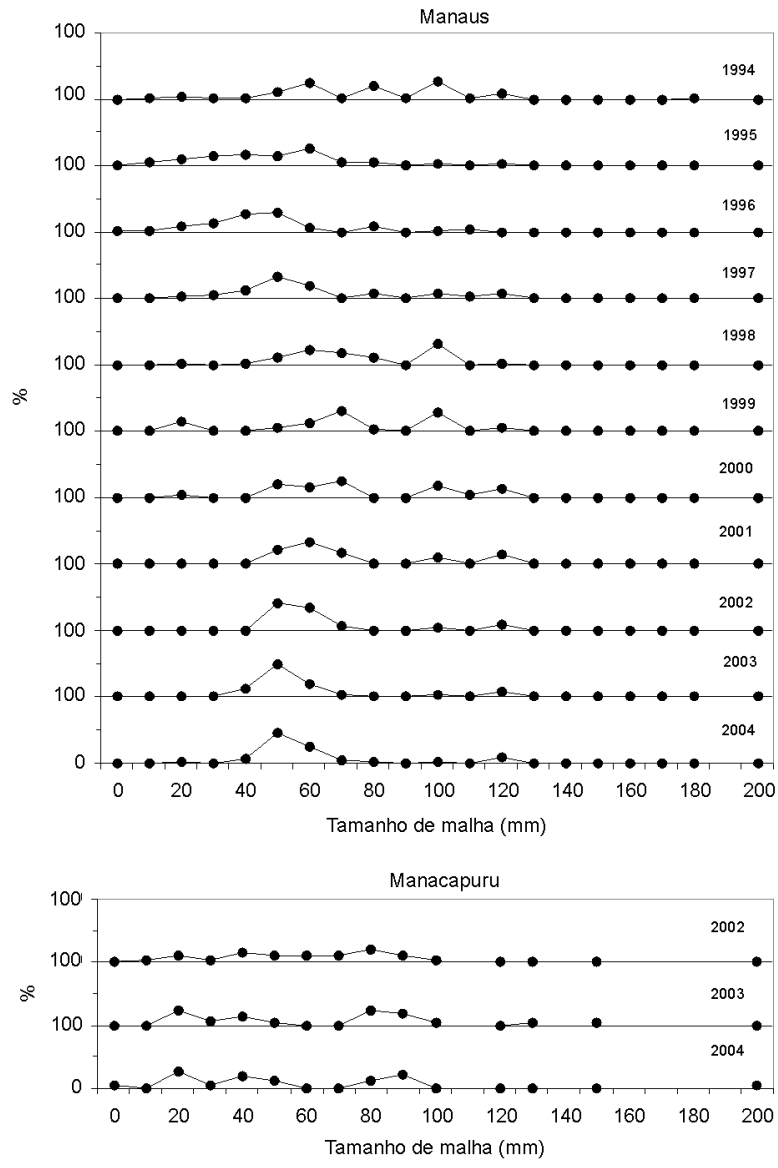

Figura 5 - Freqüência relativa dos tamanhos de malha (nós opostos) utilizados em malhadeiras na pesca comercial que desembarcou em Manaus (acima) entre 1994 e 2004 e Manacapuru (abaixo) entre 2002 e 2004.

principalmente entre redes com malha de $20 \mathrm{~mm}$ a $90 \mathrm{~mm}$, sem predomínio ou tendência marcante ao longo do tempo.

A composição das capturas por tamanho de malha foi analisada com os anos reunidos para reduzir o ruído gerado pelas variaçōes interanuais e focando na procura de tamanhos de malha mais produtivos. Para Manacapuru houve maior produção de apetrechos com malha de 20-30; $40-50$ e de 90-100, apresentando um resultado maior do que aquele indicado na sua frequência de uso indicado anteriormente (Figura 6a). Em Manaus, o acumulo das capturas ao longo dos anos destinou às classes de $50-60 \mathrm{~mm}$ e $60-70 \mathrm{~mm}$ a metade da produção total registrada e identificada (Figura 6b). Ao decompor esta produção para os principais pescados (Figura 6c), observamos maior variação, com tambaqui (Colossoma macropomum Cuvier, 1818) sendo capturado mais com malhas de $100-110 \mathrm{~mm}$ e de $120-130 \mathrm{~mm}$ (mais de $60 \%$ da produção total), havendo ainda um pico menor nos 60-70 mm. Este perfil é similar ao de pirapitinga (Piaractus brachypomus Cuvier, 1818), cuja produção foi maior em redes com malha de 120 $130 \mathrm{~mm}$ e $60 \%$ da produção total em malhas acima de 80 
$\mathrm{mm}$. Já tucunaré (Cichla spp.), curimatá (Prochilodus nigricans Spix \& Agassiz, 1829) e aruanã (Osteoglossum bicirrhosum Cuvier, 1829) apresentaram maior produção principalmente em malhas entre os 50 e $70 \mathrm{~mm}$, e baixíssima produção em malhas acima de $80 \mathrm{~mm}$ (menos de $8 \%$ ).
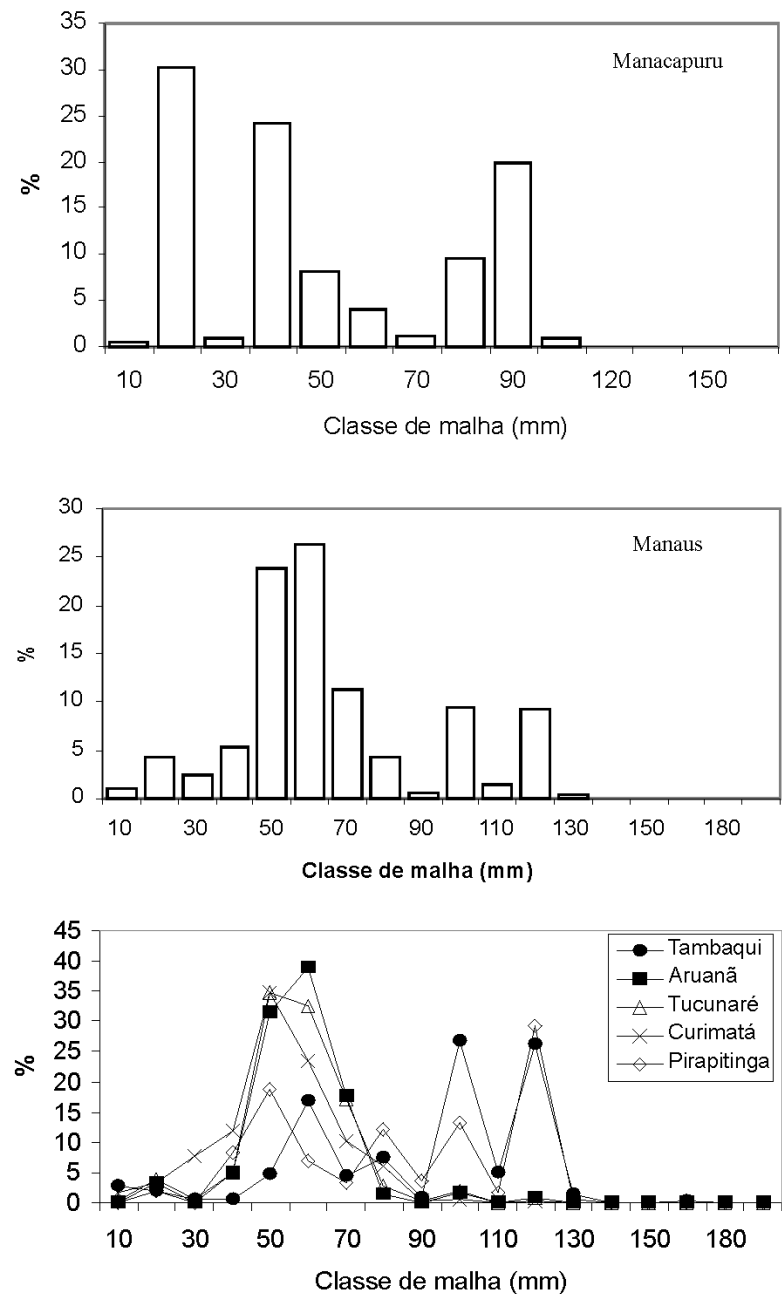

Figura 6 - Freqüência relativa acumulada por tamanho de malha da captura desembarcada entre 2001 e 2004 para Manacapuru (acima) e 1994 e 2004 para Manaus (meio), com detalhe para as principais pescados desembarcados em Manaus (abaixo).

\section{ORIGEM E TIPO DO PESCADO CAPTURADO COM MALHADEIRA}

Analisando todos os anos e subsistemas onde ocorreram as pescarias desembarcadas em Manaus (Figura 7) foi observado um padrão de maior freqüência relativa de viagens usando malhadeira para as áreas do Purus (47,8\%), baixo Solimôes $(12,9 \%)$ e médio Solimões (12,2\%). Em Manacapuru destacou-se a importância das áreas de pesca localizadas no baixo Solimões $(94,3 \%)$ e Purus $(4,4 \%)$.
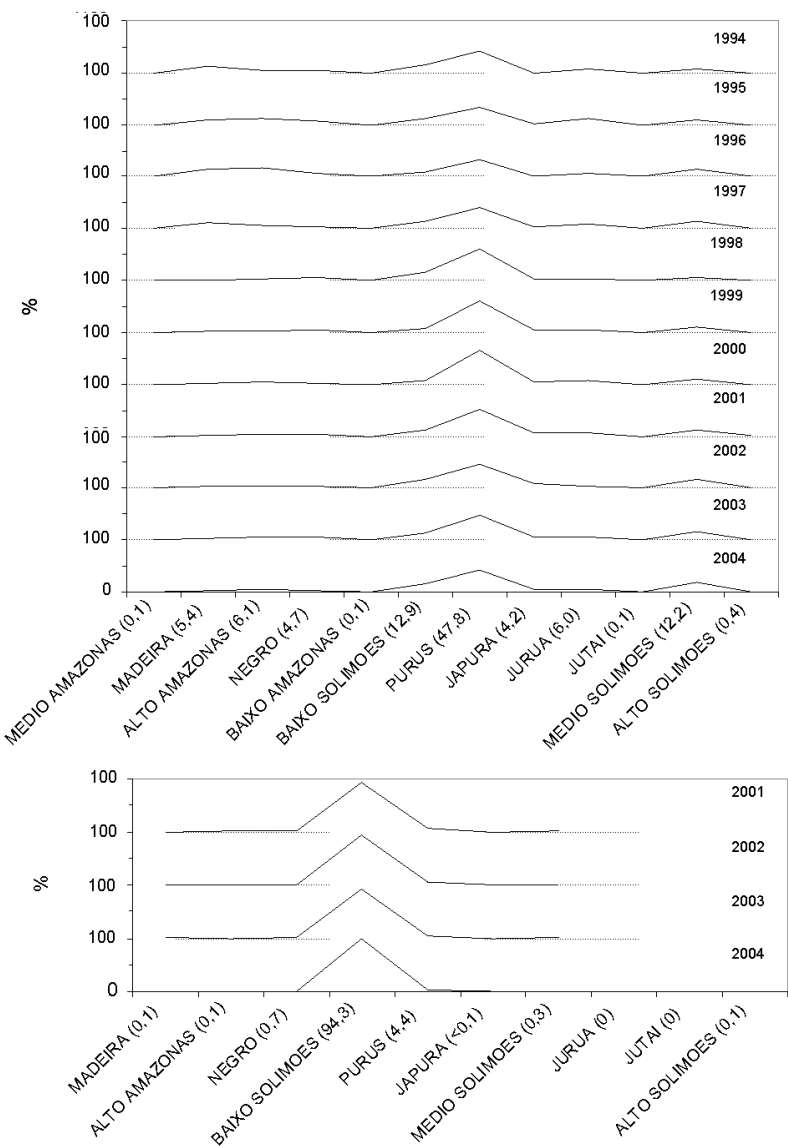

Figura 7 - Frequiência de ocorrência do uso da malhadeira nos sub-sistemas da Amazônia Central explorados pela frota desembarcou em Manaus entre 1994 e 2004 (acima) e Manacapuru entre 2001 e 2004 (abaixo).

Na comparação da composição dos pescados desembarcados com malhadeira no porto de Manacapuru e de Manaus (Figura 8), observou-se que a produção em Manacapuru é mais diversificada e eqüitativa entre os tipos de pescado, com destaque para bagres utilizados nos frigoríficos do município, como dourada e mapará, e para pescados de consumo local, como tambaqui e curimatá. Em Manaus houve predomínio de tambaqui, aruanã e tucunaré, os quais totalizaram 59\% do pescado desembarcado.

A variação temporal da participação das principais espécies no desembarque em Manaus (Figura 9) foi analisada por apresentar uma série temporal longa para os padrões nacionais (1994 a 2004). Observou-se que para aruanã houve um aumento na participação de cerca de 3\% entre 1995 e 1997 para cerca de $20-25 \%$ entre 1998 e 2003 , embora sem retornar ao pico de 32\% obtido em 1994. Curimatá apresentou participação crescente entre 1994 e 1996 e decrescente até 1998, a partir de quando se manteve estável em torno de 6\%. Já para tambaqui, houve redução na participação em torno dos $34 \%$ entre 1994 e 1995 para $7 \%$ em 1996, aumentando para 

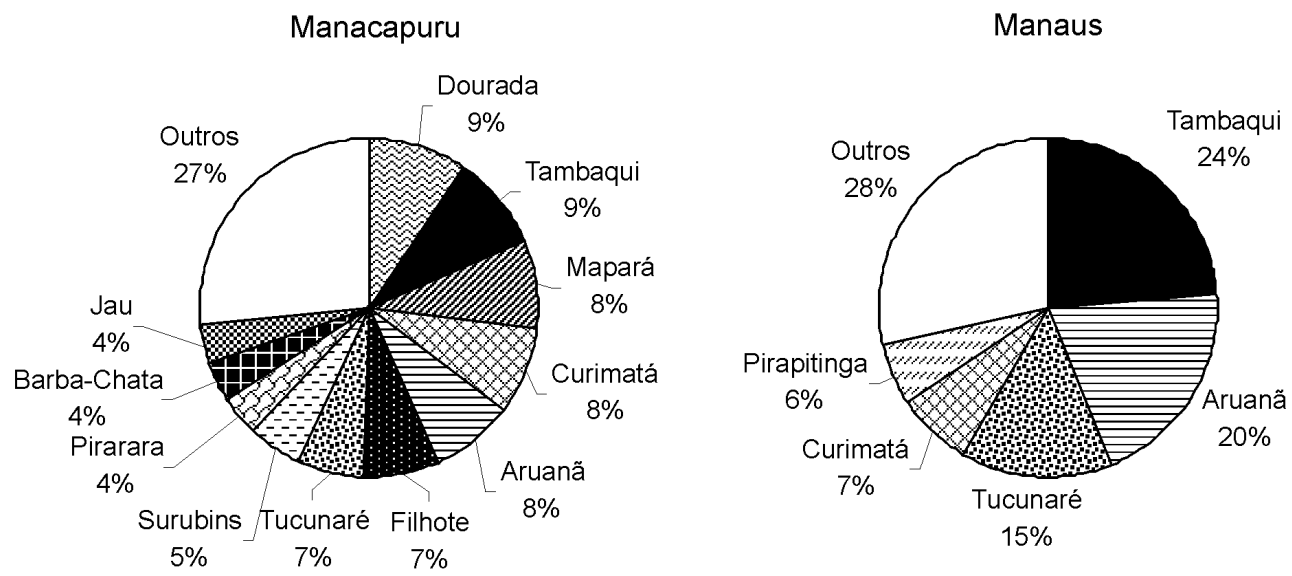

Figura 8 - Percentual do desembarque acumulado dos itens capturados com malhadeira e registrados nos portos de Manacapuru de 2001 a 2004 e de Manaus de 1994 a 2004.

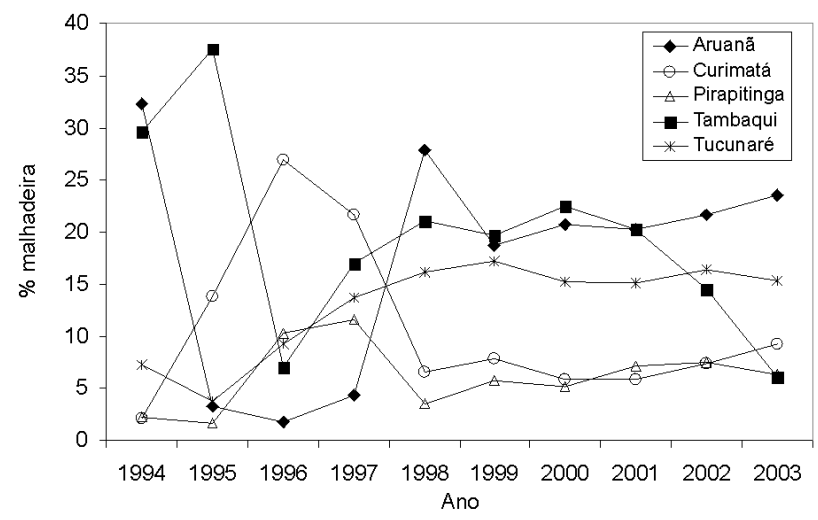

Figura 9 - Participação dos principais itens desembarcados com malhadeira em Manaus entre 1994 e 2004.

cerca de $20 \%$ entre 1997 e 2001, voltando a declinar para 14\% em 2002 e $6 \%$ em 2003. A participação de tucunaré também foi variada ao longo destes anos, sendo crescente entre 1995 e 1999 e estável em torno de 15-16\% desde então.

\section{APLICAÇÃO DAS NORMAS LEGAIS}

A Tabela 1 apresenta o levantamento anual para Manaus das pescarias nos diversos sub-sistemas com redes cujos tamanhos de malhas foram inferiores a $70 \mathrm{~mm}$, portanto passíveis de uso ilegal de acordo com a Portaria SUDEPE 466/1972 e Instrução Normativa IBAMA 47/2004. Desconsiderando as observaçōes isoladas $(\mathrm{n}<3)$, observa-se que pescarias efetuadas no Japurá, Juruá e Alto Solimôes apresentaram os menores percentuais anuais, porém, ainda assim com cerca de 50\% das viagens com malhas pequenas. Já no Alto-Amazonas e Baixo Solimóes esteve em torno dos $60 \%$ e no Negro com uma média interanual de $81 \%$ de viagens com malhadeiras de malha pequena.

Tais registros geraram uma média anual total entre $43 \%$ e $73 \%$ dos registros (Figura 10), havendo oscilação interanual com aumento da possibilidade de uso ilegal entre 1994-1996 e 2001-2004 e redução entre 1996 e 1999.

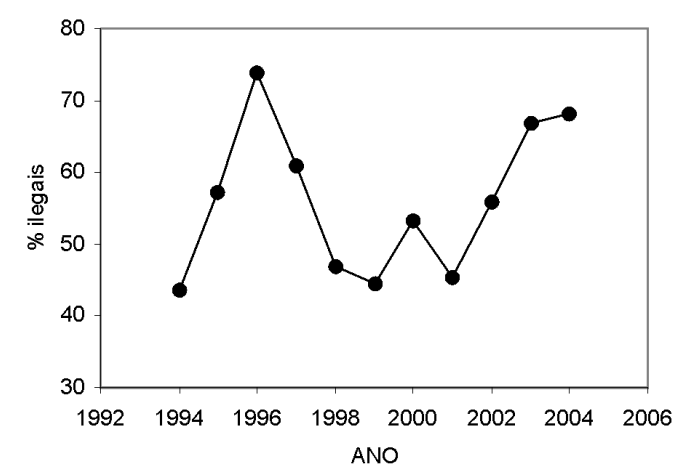

Figura 10 - Percentual de malhadeiras com uso possivelmente ilegal registradas no porto de Manaus entre 1994 e 2004. 
Tabela 1 - Distribuição e ocorrência relativa das viagens com malhadeiras que apresentaram malhas possivelmente ilegais (<70 mm nós opostos) registradas em Manaus entre 1994 e 2004, por sub-sistemas na Amazônia Central.

\begin{tabular}{|c|c|c|c|c|c|c|c|c|c|c|c|c|c|c|c|c|c|c|c|c|c|c|}
\hline \multirow{2}{*}{ Sub-Sistema } & \multicolumn{2}{|c|}{1994} & \multicolumn{2}{|c|}{1995} & \multicolumn{2}{|c|}{1996} & \multicolumn{2}{|c|}{1997} & \multicolumn{2}{|c|}{1998} & \multicolumn{2}{|c|}{1999} & \multicolumn{2}{|c|}{2000} & \multicolumn{2}{|c|}{2001} & \multicolumn{2}{|c|}{2002} & \multicolumn{2}{|c|}{2003} & \multicolumn{2}{|c|}{2004} \\
\hline & $\%$ & $\mathrm{n}$ & $\%$ & $\mathrm{n}$ & $\%$ & $\mathrm{n}$ & $\%$ & $\mathrm{~N}$ & $\%$ & $\mathrm{n}$ & $\%$ & $\mathrm{n}$ & $\%$ & $\mathrm{n}$ & $\%$ & $\mathrm{n}$ & $\%$ & $\mathrm{n}$ & $\%$ & $\mathrm{n}$ & $\%$ & $\mathrm{n}$ \\
\hline Alto Solimões & 0 & 1 & 100 & 1 & 67 & 6 & 100 & 1 & 0 & 1 & 17 & 6 & 100 & 1 & 0 & 1 & 100 & 1 & & & 0 & 1 \\
\hline Jutai & 0 & 2 & & & & & 100 & 1 & 50 & 2 & & & & & & & & & & & & \\
\hline Juruá & 29 & 7 & 43 & 14 & 78 & 9 & 50 & 8 & 40 & 5 & 50 & 6 & 43 & 7 & 50 & 4 & 50 & 2 & 40 & 5 & 60 & 5 \\
\hline Médio Solimões & 40 & 5 & 50 & 12 & 78 & 9 & 56 & 9 & 57 & 7 & 50 & 8 & 57 & 7 & 40 & 5 & 40 & 5 & 50 & 6 & 71 & 7 \\
\hline Japurá & 0 & 1 & 71 & 7 & 75 & 4 & 71 & 7 & 0 & 3 & 43 & 7 & 29 & 7 & 33 & 6 & 33 & 6 & 60 & 5 & 43 & 7 \\
\hline Purus & 40 & 10 & 46 & 13 & 67 & 9 & 46 & 13 & 50 & 14 & 50 & 10 & 56 & 9 & 50 & 8 & 29 & 7 & 63 & 8 & 60 & 10 \\
\hline Baixo Solimões & 57 & 7 & 55 & 11 & 86 & 7 & 60 & 10 & 56 & 9 & 43 & 7 & 50 & 6 & 50 & 8 & 67 & 6 & 75 & 4 & 86 & 7 \\
\hline Negro & 100 & 4 & 100 & 5 & 67 & 9 & 75 & 4 & 57 & 7 & 60 & 5 & 100 & 3 & 50 & 4 & 100 & 3 & 100 & 3 & 100 & 2 \\
\hline Alto Amazonas & 43 & 7 & 55 & 11 & 78 & 9 & 67 & 9 & 50 & 6 & 43 & 7 & 60 & 5 & 75 & 4 & 100 & 2 & 100 & 3 & 80 & 5 \\
\hline Madeira & 50 & 8 & 58 & 12 & 70 & 10 & 63 & 8 & 20 & 5 & 33 & 6 & 67 & 3 & 33 & 3 & 100 & 1 & 100 & 2 & 100 & 2 \\
\hline Médio Amazonas & & & & & & & 100 & 1 & 100 & 1 & & & & & & & & & & & & \\
\hline Não Identificado & 33 & 3 & 80 & 5 & & & 67 & 3 & 50 & 2 & 100 & 1 & 0 & 1 & & 1 & 100 & 1 & & & 100 & 1 \\
\hline
\end{tabular}

\section{DISCUSSÃO}

Redes de espera ou malhadeiras são apetrechos amplamente utilizados em pescarias de pequena escala devido a sua versatilidade e ao baixo custo em equipamento e trabalho (Reis \& Pawson 1992). Embora não seja citada com frequêencia no passado (Veríssimo, 1895; Meschkat, 1961), seu uso se tornou comum na década de 1970 devido a maior disponibilidade das linhas sintéticas (McGrath et al., 1993; Batista et al., 2004). Malhadeiras são adequadas para uso em sistemas multiespecíficos, típicos de ambientes tropicais como a Amazônia, por apresentar elevada seletividade determinada por suas características físicas e operacionais (Hamley, 1975), embora a alta diversidade destes ambientes reduza a eficácia desta seleção.

A malhadeira é um aparelho frequentemente utilizado em pescarias com produção desembarcada nos portos de Manaus e Manacapuru, capturando uma variedade de espécies que são comercialmente importantes na região (Batista, 1998). Entretanto, a produção desembarcada capturada com a utilização deste apetrecho decresceu ao longo dos anos em Manaus, embora os desembarques totais tenham se mantido estáveis e mesmo maiores em anos recentes (IBAMA 2003, 2005, 2006). Como o principal mercado consumidor de pescado na região segue sendo Manaus, de forma ainda mais destacada por seu aumento populacional, podemos interpretar que, realmente, há menor uso da malhadeira nas viagens de pesca.

Particular cuidado no monitoramento das capturas deve ser efetuado entre os meses de outubro, novembro e dezembro, período correspondente as águas baixas do ciclo anual de inundação. $\mathrm{O}$ uso preferencial da malhadeira na época de seca em comparação com a época chuvosa não é típico, dado que a versatilidade do apetrecho permite a geração de produção similar ao longo de todo o ano, como o informado por Petrere (1978) para a pesca comercial de Manaus na década de 1970, por Smith (1979) para pescarias na região de Itacoatiara, no alto rio Amazonas, e por Cerdeira et al. (2000) para a região de Monte Alegre, médio rio Amazonas.

Embora tenha sido observada maior produção em determinados tamanhos de malha, não podemos considerar que haja um padrão definido de um determinado tamanho de malha por espécie, mas sim uma ampla diversidade de opções em duas categorias, malhadeiras de malha menor de $80 \mathrm{~mm}$ para caraciformes migradores de pequeno e médio porte e malhadeiras com malha maior de $80 \mathrm{~mm}$ para espécies e espécimes de maior porte. Isto é interessante em particular para Colossoma macropomum, o qual teve seu exemplar juvenil chamado regionalmente de ruelo sendo capturado na malha $60 \mathrm{~mm}$ e o adulto (chamado de tambaqui) em malhadeiras maiores que $100 \mathrm{~mm}$.

Petrere (1978) mencionou que o emprego de determinados tamanhos de malha são ideais na captura de espécies como tambaqui (malhas de 150 a $300 \mathrm{~mm}$ entre nós opostos) e pescada $(70$ a $100 \mathrm{~mm})$. Entretanto a avaliação dos resultados dos tamanhos de malhas que mais capturaram tambaqui no presente trabalho, indicaram a utilização de malhas menores, as quais possivelmente permitiram a captura de indivíduos mais jovens que os capturados na década de 1970 . O uso de malhas de tamanho menor é um dos fatores responsáveis pela redução das capturas (Welcomme, 1997), sendo o aumento do tamanho de malha um instrumento de manejo da pesca tradicional (Jones, 1983; Heikinheimo et al., 2006), o qual é de difícil aplicação em pescarias multiespecíficas como a Amazônica.

A frota que desembarcou em Manaus utilizou malhadeiras principalmente no rio Purus ( $48 \%$ das pescarias), com destaque 
na maioria dos trimestres. Este rio também se destacou nas análises de Batista \& Petrere (2003) como origem dos barcos de pesca que desembarcaram em Manaus entre 1994 e 1996, porém sendo usado em cerca de $36 \%$ das viagens de pesca, o que indica ter ocorrido uso recente ainda em maior frequêencia. Assim, temos uma forte indicação de haver maior preferência por este apetrecho neste rio em relação ao padrão geral.

Já no desembarque em Manacapuru, o registro de que a grande maioria das pescarias com malhadeira ocorreram no baixo Solimões, usualmente próximos a sede municipal, sendo indicador do perfil local do mercado deste centro, que apresenta frota seja composta por embarcações de tamanho similar ao de Manaus (Batista, 2003), mas mercado com demanda tradicional do Estado. Este resultado também tinha sido evidenciado por Batista (1998) ao verificar que o deslocamento do pescador comercial é de cerca de $20 \mathrm{~km}$.

Manaus apresentou um desembarque com menos espécies principais do que Manacapuru, indicando ser um mercado mais seletivo que o do interior, o qual se assemelha mais à elevada diversidade observada no consumo de subsistência de comunidades rurais (Smith, 1979; Batista et al., 1998).

As variações na participação dos diferentes pescados nas capturas efetuadas com malhadeiras entre 1994 e 2003 indicam que há uma redução da importância do tambaqui, o que é mais notório comparando com a participação de 95\% na produção das malhadeiras em 1976 (Petrere, 1978). Paralelamente, se observa a estabilidade ou crescimento suave da participação de outros pescados principais, indicando que o caso do tambaqui, em particular, é mais crítico. Esta espécie tem apresentado seguidos sinais de sobrepesca (Isaac \& Ruffino, 1996; Batista \& Petrere, 2003), embora seja a única espécie com defeso reprodutivo anual desde 1989 e com tamanho mínimo de captura pelo menos desde 1975 (Portaria SUDEPE 47/1975).

A Instrução Normativa IBAMA 43/2004 revogou a antiga Portaria SUDEPE 466/72, válida em todo território nacional, porém não modificou suas restrições com relação ao tamanho de malha especificado. Esta Instrução Normativa não substitui as normatizações das bacias que possuem instrumentos específicos restringindo o uso de aparelhos e métodos de pesca, portanto ressalta-se a importância da caracterização do uso da malhadeira para as regiōes de abrangência das frotas que abastecem os principais portos. Para o pescador é mais barato comprar malhadeiras de $100 \mathrm{~m}$, evitando a ilegalidade evidente, assim como é mais interessante devido à facilidade de encontrá-la nos mercados. Não há assim um efeito prático se a fiscalização não ocorrer em campo, o que, entretanto, é uma medida inviável em larga escala e mais apropriada para existir em acordos de pesca locais (e.g. Ribeiro \& Fabré, 2003).

Isaac et al. (1993) apontaram diversas incoerências, desarmonias e lacunas na legislação pesqueira que afetam a pesca na Amazônia, assim como Batista et al. (2004) apontaram que há pouco cuidado por parte de órgãos governamentais com a gestão integrada da pesca no Brasil, que as normas são inadequadas e que as limitaçôes dos apetrechos, adequadas ou inadequadas para a bacia Amazônica, não são cumpridas. $\mathrm{O}$ não cumprimento das normas vigentes é em grande parte devido à escassa fiscalização pelos órgãos competentes, e também pela grande área de abrangência da geografia Amazônica, mas fundamentalmente está relacionada com a inadequação dos instrumentos de manejo constantes nas normativas à cultura, dinâmica e escala regionais, logo é necessário repensar as ações e normas existentes e efetuar um ordenamento efetivo, atendendo a claros objetivos de manejo e sendo monitorado continuamente.

Sugere-se que uma discussão seja desencadeada de forma a sistematizar o ordenamento pesqueiro focado na região, eliminando normas federais com especificações exageradas, focando apenas em diretrizes e normas gerais. O ordenamento seria então complementado com normas reguladoras regionais que indicariam características mínimas a serem respeitadas nos acordos de pesca locais a partir da experiência dos usuários locais e do conhecimento técnico-científico disponível. As experiências práticas em águas continentais que têm sido efetuadas devem servir como lições adaptativas para reflexão, sendo fundamental que tenham seus efeitos profundamente avaliados e que haja disposição das instituiçōes de aprender com tais lições.

\section{AGRADECIMENTOS}

Os autores agradecem aos pescadores de Manaus e Manacapuru por sua boa vontade em participar da pesquisa com suas informações. Agradecemos ainda a colaboração de Tony P. Braga, Joel, Francisca C. Silva, Ligia, Luiza por seu trabalho na coleta de dados e processamento em laboratório. A pesquisa foi apoiada pelo Conselho Nacional de Desenvolvimento Científico e Tecnológico (CNPq), ProVárzea/IBAMA, Fundo Nacional do Meio Ambiente (FNMA) e Universidade Federal do Amazonas (UFAM).

\section{BIBLIOGRAFIA CITADA}

Barthem, R.B.; Petrere Jr., M.; Isaac, V.N.; Ribeiro, M.C.L. De B.; Mcgrath, D.G.; Vieira, I.J.A.; Barco, N.V. 1997. A pesca na Amazônia: problemas e perspectivas para o seu manejo. In: Valadares-Pádua, C.; Bodmer, R.E.; Cullen Jr., L. (Eds.) Manejo de vida silvestre para a conservação no Brasil. CNPq/Sociedade Civil Mamirauá, Belém, Pará. p. 173-185.

Batista, V.S. 1998. Distribuição, dinâmica da frota e dos recursos pesqueiros da Amazônia Central. Tese de Doutorado, INPA/ UFAM, Manaus, Amazonas. 292pp.

Batista, V.S.; Inhamuns, A.J. ; Freitas, C.E.C.; Freire-Brasil, D. 1998. Characterization of the fishery in riverine communities in the 
Low-Solimões/High-Amazon region. Fisheries Management and Ecology, 5:419-435.

Batista, V.S. 2003. Caracterização da frota pesqueira de Parintins, Itacoatiara e Manacapuru, Estado do Amazonas. Acta Amazonica, 33(2):291-302.

Batista, V.S.; Petrere Jr., M. 2003. Characterization of the commercial fish production landed at Manaus, Amazonas state, Brazil. Acta Amazonica, 33(1):53-66.

Batista V.S.; Isaac V.J.; Viana J.P. 2004. Capítulo 2 - Exploração e manejo dos recursos pesqueiros da Amazônia. In: Ruffino, M.L. (Org.) A pesca e os recursos pesqueiros na Amazônia. IBAMA, Manaus, Amazonas, p. 63-151.

Cerdeira R.G. P.; Ruffino, M.L.; Isaac V.J. 2000. Fish catches among riverside communities around Lago Grande de Monte Alegre, Lower Amazon, Brazil. Fisheries Management and Ecology, 7(4): 355-374.

Falabela, P.G.R. 1994. A pesca no Amazonas: problemas e soluçôes. 2 ed. Imprensa oficial, Manaus, Amazonas. 180 pp.

Hamley, J.M. 1975. Review of gill-net selectivity. Journal of the Research Board of Canada 32: 1943-1969.

Heikinheimo, O.; Setala, J.; Saarni, K.; Raitaniemi, J. 2006. Impacts of mesh-size regulation of gillnets on the pikeperch fisheries in the Archipelago Sea, Finland. Fisheries Research, 77: 192-199.

IBAMA 2003. Estatística pesqueira do Amazonas e Pará - 2001. IBAMA/ProVárzea, Manaus, Amazonas. 173 pp.

IBAMA 2005.Estatística Pesqueira do Amazonas e Pará - 2002. IBAMA/ProVárzea, Manaus, Amazonas. 84 pp.

IBAMA 2006.Estatística Pesqueira do Amazonas e Pará - 2003. IBAMA/ProVárzea, Manaus, Amazonas. 76 pp.

Isaac, V.J.; Rocha V.L.C.; Mota, S. 1993.Considerações sobre a legislação da "piracema" e outras restriçōes da pesca da região do Médio Amazonas. In: Furtado, L.G.; Mello, A.F.; Leitão, W. (Eds.) Povos das águas: realidade e perspectiva na Amazônia. Museu Paraense Emilio Goeldi, Belém, Pará. p. 187-211.

Isaac, V.J.; Ruffino, M.L. 1996. Population dynamics of tambaqui, Colossoma macropomum Cuvier 1818, in the Lower Amazon, Brazil. Fisheries Management and Ecology, (3): 315-333.
Jones, R. 1984. Mesh size regulation and its role in fisheries management. In: Papers presented at the Expert Consultation on the regulation of fishing effort (fishing mortality). Rome, 17-26 January 1983. A preparatory meeting for the FAO World Conference on fisheries management and development. FAO Fisheries Report, Roma, Itália, 289(Suppl.2): 219pp.

McGrath, D.G.; Castro, F.; Futemma, C.; Amaral, B.D.; Calabria,J. 1993. Fisheries and the evolution of resource management on the lower Amazon floodplain. Human Ecology, (2): 167-195.

Merona, B.; Bittencourt, M.M. 1988. A pesca na Amazônia através dos desembarques no mercado de Manaus: Resultados preliminares. Memoria Sociedad de Ciencias Naturales La Salle, Caracas, Venezuela, XLVIII (Suplemento): 433-453.

Meschkat, A. 1961.Report to the government of Brazil on the fisheries of the Amazon region. FAO Expanded Technical Assistance Program, Roma, 1305: 77pp.

Petrere Jr., M. 1978. Pesca e esforço de pesca no estado do Amazonas. II - Locais e aparelhos de captura e estatística de desembarque. Acta Amazonica, 8(Supl. 2): 1-54.

Petrere Jr., M. 1985. A pesca comercial no rio Solimões-Amazonas e seus afluentes: Análise do pescado desembarcado no Mercado Municipal de Manaus (1976-1978). Ciência e Cultura, 37(12): 1987-1999.

Reis, E.G.; Pawson, M.G. 1992. Determination of gillnet selectivity for bass (Dicentrarchus labrax L.) using commercial catch data. Fisheries Research, 13: 173-187.

Ribeiro, M.O.A.; Fabré, N.N. 2003. Sistemas Abertos Sustentáveis (SAS): Uma alternativa de gestão ambiental na Amazônia. Publ. EDUA, Manaus, Amazonas, 278pp.

Smith, N.J.H. 1979.A pesca no rio Amazonas. INPA, Manaus, Amazonas, 154pp.

STATSOFT. 1999. Electronic Statistics Textbook. www.statsoft.com/ textbook/stathome.html, acessado em 15 de outubro de 2006.

Veríssimo, J. 1895. A pesca na Amazônia. Livraria Clássica Alves, Rio de Janeiro, 206pp.

Welcomme, R.L. 1997. Inland fisheries. FAO Technical Guidelines for Responsible Fisheries, Roma, Itália, 6: 36 pp.

Recebido em 01/12/2006

Aceito em 13/02/2009 
